\title{
Capaian Indikator Kapitasi Berbasis Komitmen Pelayanan pada Puskesmas di Kota Semarang
}

\author{
Achievements Of Capacity Indicators Based On Service Commitments \\ In Primary Health Care In Semarang
}

\author{
Anton Kristijono*) \\ Jurusan Rekam Medis dan Informasi Kesehatan; Poltekkes Kemenkes Semarang \\ Jl. Tirto Agung ; Pedalangan ; Banyumanik; Semarang \\ E-mail: kristijono_health@yahoo.co.id
}

\begin{abstract}
Start from 2017, the capitation payment based on the fulfilment of service commitment has been implemented throughout all FKTP in Indonesia. There are three ration indicators of service commitment: contact number ( $\geq 150$ per mile), ratio of participants of Prolanis who regularly visit $(\geq 50 \%)$, and the ratio of non-specialistic outpatient referral $(\leq 5 \%)$. The achievement of indicator target shows the service quality and influences the amount of capitation rate obtained by the Community Health Centre from BPJS Kesehatan. The research objective is to identify the glimpse of the achievement of the three indicators and the achievement of capitation number in 37 (thirty seven) Community Health Centres in Semarang City in 2018 and Semester 1 of 2019. The research method is descriptive observational, where during the the research, there has not been any intervention implemented. The data type used is quantitative data obtained from the secondary data of BPJS Kesehatan, Department of Health of Semarang City and Community Health Centres.

The research result describes the average achievement of Contact Number of semester 1 and 2 in 2018 which reached 156.43 per mile and 157.08 per mile bigger that the indicator target, semester 1 of 2019 was 144.99 per mile, under the indicator target. Prolanis ratio describes that the Prolanis participants registered in Community Health Centres in Semarang City who regularly pay a visit to the Community Health Centres to obtain the service over chronic diseases they suffer continuously. Non-specialistic outpatient referral ratio suggests that the service quality in Community Health Centres in Semarang city is good. The average achievement of capitation payment based on the service commitment of the same period respectively is: $97,74 \% ; 98,07 \%$; $98,07 \%$. Community Health Centre of Karanganyar has the lowest average achievement of capitation payment in 2018 as well as in Semester 1 of 2019 of $92.50 \%$ which shows that in average, there are 2 (two) indicators of capitation payment based on service commitment in Community Health Centres of Karanganyar which is located in unsafe zone during that period.
\end{abstract}

Keyword: Capitation; a capitation indicator based on service commitment

\begin{abstract}
Abstrak
Mulai tahun 2017 pembayaran kapitasi berbasis pemenuhan komitmen pelayanan dilaksanakan di seluruh FKTP di Indonesia. Terdapat tiga rasio indikator komitmen pelayanan : angka kontak $(\geq 150$ per mil), rasio peserta prolanis rutin berkunjung $(\geq 50 \%)$, dan rasio rujukan rawat jalan non spesialistik ( $\leq 5 \%)$. Pencapaian target indikator menunjukan kualitas pelayanan dan mempengaruhi besaran tarif kapitasi yang didapat Puskesmas dari BPJS Kesehatan. Tujuan penelitian untuk mengetahui gambaran pencapaian ketiga indikator dan capaian besaran kapitasi pada 37 (tigapuluh tujuh) Puskesmas di Kota Semarang tahun 2018 dan semester 1 tahun 2019. Jenis penelitian adalah observasional deskriptif, dimana selama penelitian berlangsung tidak dilakukan intervensi. Jenis data yang digunakan : data kuantitatif, yang berasal dari data sekunder BPJS Kesehatan, Dinas Kesehatan Kota Semarang.
\end{abstract}


Hasil penelitian menggambarkan rata-rata capaian Angka Kontak semester 1 dan semester 2 tahun 2018 mencapai 156,43 per mil dan 157,08 per mil lebih besar dari target indikator, semester 1 tahun 2019 adalah 144,99 per mil, di bawah target indikator. Rata-rata capaian peserta Prolanis rutin berkunjung dan rata-rata capaian rasio rujukan rawat jalan non spesialistik pada periode yang sama, hasilnya di atas target indikator. Rata-rata capaian pembayaran kapitasi pada periode yang sama berturut-turut : 97,74\%; 98,07\%; 98,07\%. Puskesmas Karanganyar rata-rata capaian pembayaran kapitasinya terendah selama tahun 2018 serta semester 1 tahun 2019 sebesar 92,50\%.

Kata kunci : Kapitasi; Indikator kapitasi berbasis komitmen pelayanan

\section{Pendahuluan}

Sejak diundangkannya UndangUndang Nomor 40 tahun 2004 tentang Sistem Jaminan Sosial Nasional (SJSN) dan mulai diberlakukannya program Jaminan Kesehatan Nasional pada tahun 2014, masyarakat Indonesia mulai memasuki tahapan baru dalam pelaksanaan sistem kesehatan nasional. Jaminan Kesehatan Nasional atau JKN adalah jaminan berupa perlindungan kesehatan agar peserta memperoleh manfaat pemeliharaan kesehatan dan perlindungan dalam memenuhi kebutuhan dasar kesehatan yang diberikan kepada setiap orang yang telah membayar iuran atau iurannya dibayar oleh pemerintah.

BPJS Kesehatan sesuai kewenangannya membuat kesepakatan dengan fasilitas kesehatan (faskes) mengenai besar pembayaran faskes yang mengacu pada standar tarif yang ditetapkan oleh pemerintah serta membuat/menghentikan kontrak kerja dengan faskes (pasal 11 UU No. 24 tahun 2011). Kesepakatan atau kerjasama tersebut salah satunya adalah dengan Pusat Kesehatan Masyarakat (Puskesmas) sebagai salah satu fasilitas kesehatan tingkat pertama (FKTP).

Mulai tahun 2017 pembayaran kapitasi berbasis pemenuhan komitmen pelayanan dilaksanakan di seluruh FKTP di Indonesia. Terdapat tiga rasio indikator komitmen pelayanan : angka kontak $(\geq 150$ per mil), rasio peserta prolanis rutin berkunjung $(\geq 50 \%)$, dan rasio rujukan rawat jalan non spesialistik $(\leq 5 \%)$. Pencapaian target indikator menunjukan kualitas pelayanan dan mempengaruhi besaran tarif kapitasi yang didapat Puskesmas dari BPJS Kesehatan.

\section{Metode}

Jenis penelitian yang digunakan adalah observasional deskriptif, dimana selama penelitian berlangsung tidak dilakukan intervensi. Jenis data yang digunakan adalah data kuantitatif, yang berasal dari data sekunder BPJS Kesehatan, Dinas Kesehatan Kota Semarang dan Puskesmas. Lokasi penelitian adalah di kantor BPJS Kesehatan Kedeputian Wilayah Jawa Tengah dan DIY bagian Analisis Monitoring dan Evaluasi Jaminan Pembiayaan khususnya pada bidang Penjamin Manfaat Primer BPJS Kesehatan dan Dinas Kesehatan Kota Semarang.

Subjek dalam penelitian ini meliputi: Kepala Bidang Penjamin Manfaat Primer (PMP) BPJS Kesehatan Kedeputian Wilayah Jawa Tengah dan DIY, Staf Monitoring dan Evaluasi Jaminan Pembiayaan BPJS Kesehatan Kedeputian Jawa Tengah dan DIY, Seksi Informasi dan Pengendalian Sarana Kesehatan Dinas Kesehatan Kota Semarang.

Sedangkan obyek dalam penelitian ini adalah indikator-indikator utama dalam kapitasi berbasis komitmen pelayanan yaitu indikator Angka Kontak, Rasio Rujukan Pasien Non Spesialistik dan Rasio Peserta Prolanis serta besaran kapitasi yang diterima oleh Puskesmas.

Metode Pengambilan Data dalam penelitian ini menggunakan : (1) Studi Dokumentasi, terdapat dua jenis dokumen yang digunakan dalam studi dokumentasi yaitu: data sekunder tentang pencapaian 3 (tiga) indikator utama dan besaran pembayaran Kapitasi Berbasis 
Komitmen Pelayanan 37 (tiga puluh tujuh) Puskesmas di kota Semarang yang didapatkan dari BPJS Kesehatan Kedeputian Wilayah Jawa Tengah dan DIY, yang dilengkapi dengan Wawancara (Interview).

Penelitian ini menggunakan teknik analisis deskriptif kualitatif dengan menginterpretasikan angka ketercapaian indikator kapitasi berbasis komitmen pelayanan dan penyesuaian besaran tarif kapitasi berdasarkan hasil penilaian pencapaian indikator pada 37 (tiga puluh tujuh) Puskesmas di kota Semarang selama tahun 2018 dan semester 1 tahun 2019.

\section{Hasil dan Pembahasan}

a. Hasil penelitian menggambarkan ratarata capaian Angka Kontak (AK) semester 1 dan semester 2 tahun 2018 mencapai 156,43 per mil dan 157,08 per mil lebih besar dari target indikator, semester 1 tahun 2019 adalah 144,99 per mil, di bawah target indikator.

Angka Kontak di atas indikator menggambarkan tingkat aksesibilitas dan pemanfaatan Puskesmas di kota Semarang oleh peserta BPJS Kesehatan yang terdaftar di masing-masing Puskesmas sudah baik,

Grafik 1 Rata-rata Capaian Angka Kontak Puskesmas di Kota Semarang Semester 1 tahun 2019

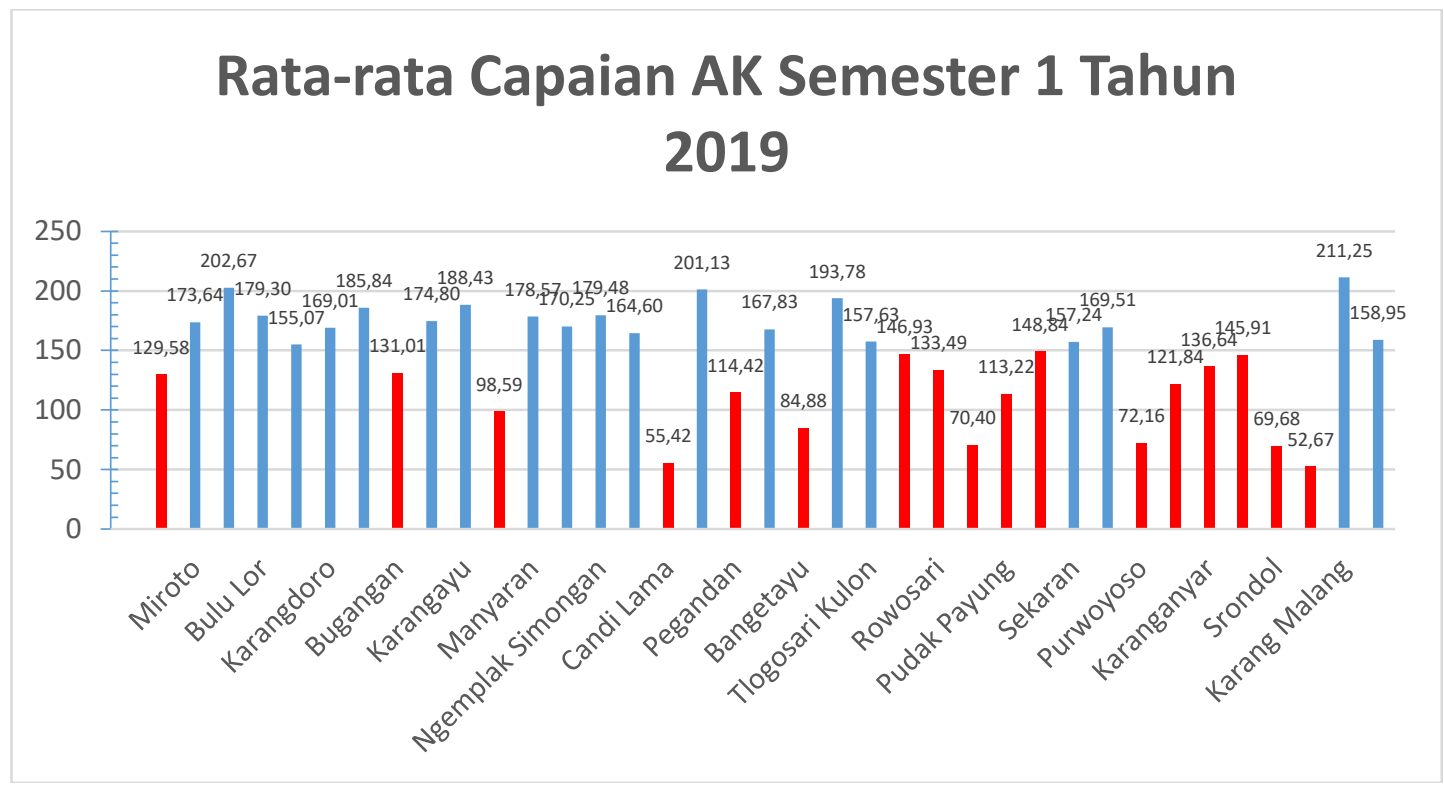

b. Rata-rata capaian peserta Prolanis rutin berkunjung dan rata-rata capaian rasio rujukan rawat jalan non spesialistik pada periode yang sama, hasilnya di atas target indikator.

Rasio Prolanis menggambarkan bahwa peserta Prolanis yang terdaftar di Puskesmas di wilayah kota Semarang rutin berkunjung ke Puskesmas untuk mendapatkan pelayanan penyakit kronis yang dideritanya secara berkesinambungan.
Rasio rujukan rawat jalan non spesialistik menunjukkan bahwa kualitas pelayanan di Puskesmas wilayah kota Semarang sudah baik, sehingga sistem rujukan terselenggara sesuai dengan indikasi medis dan kompetensi dari Puskesmas.

c. Rata-rata capaian pembayaran kapitasi berbasis komitmen pelayanan pada periode yang sama berturut-turut : $97,74 \%$; 98,07\%; $98,07 \%$ 
Tabel 1 Kriteria Penerapan Pembayaran Kapitasi Berbasis Pemenuhan Komitmen Pelayanan

\begin{tabular}{|c|c|c|c|}
\hline \multirow{2}{*}{ No } & \multicolumn{2}{|c|}{$\begin{array}{c}\text { Jumlah Pencapaian Target } \\
\text { Indikator }\end{array}$} & \multirow{2}{*}{ \% Pembayaran } \\
\cline { 2 - 3 } & Zona Tidak Aman & Zona Aman & $100 \%$ \\
\hline 1 & 0 & 3 & $95 \%$ \\
\hline 2 & 1 & 2 & $92.5 \%$ \\
\hline 3 & 2 & 1 & $90 \%$ \\
\hline 4 & 3 & 0 & \\
\hline
\end{tabular}

Sumber: Peraturan Bersama Sekjend Kemenkes dan Dirut BPJS Kesehatan tahun 2017

Grafik 2 Rata-rata Capaian Pembayaran Kapitasi Berbasis Komitmen Pelayanan Puskesmas di Kota Semarang Semester 1 tahun 2019

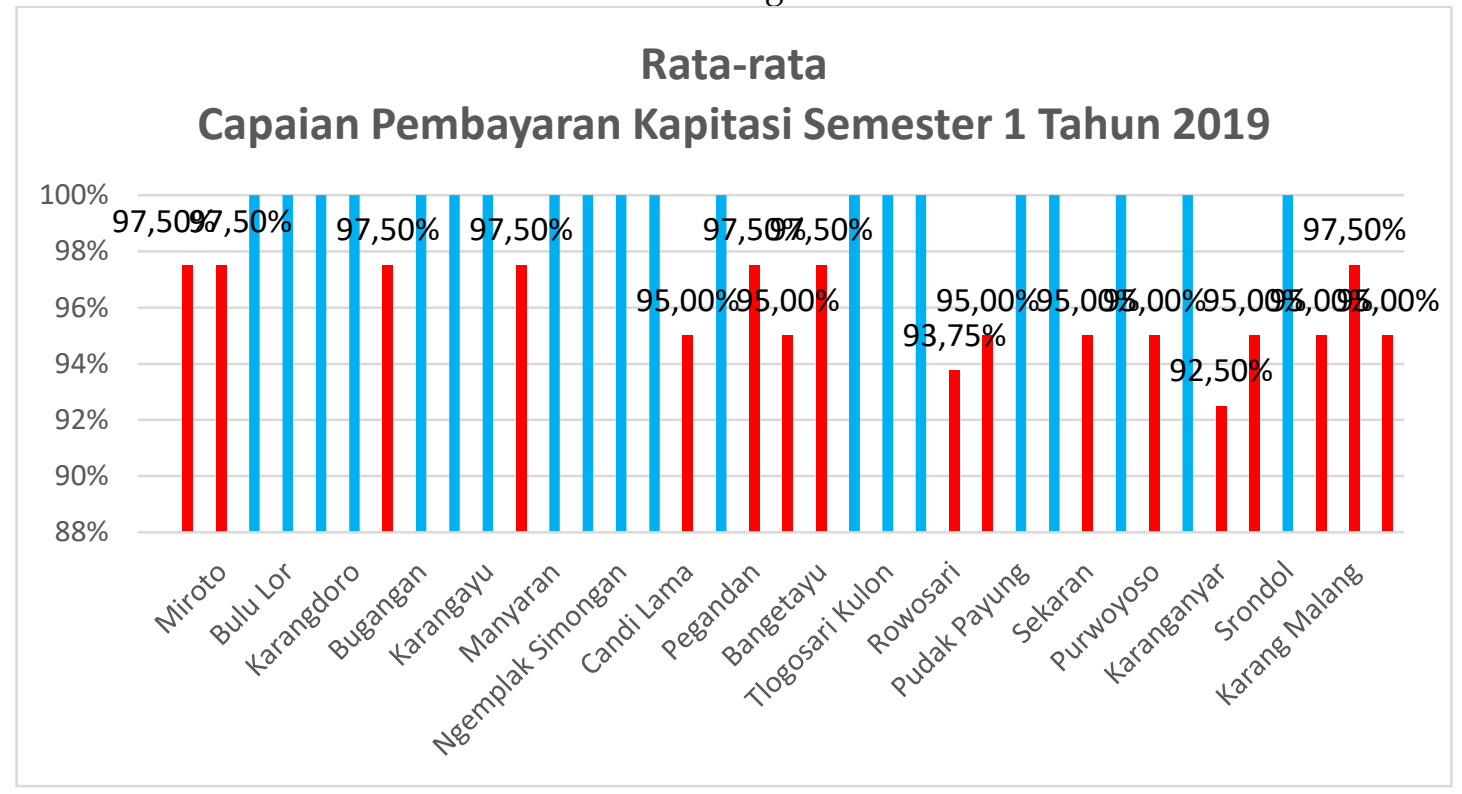

Puskesmas Karanganyar rata-rata capaian pembayaran kapitasinya terendah selama tahun 2018 serta semester 1 tahun 2019 sebesar 92,50\%, hal menunjukkan bahwa rata-rata ada 2 (dua) indikator pembayaran kapitasi berbasis komitmen pelayanan di Puskesmas Karanganyar yang berada di zona tidak aman selama periode tersebut.

\section{Simpulan dan Saran}

a. Rata-rata capaian Angka Kontak Puskesmas di kota Semarang pada semester 1 dan semester 2 tahun 2018 mencapai 156,43 per mil dan 157,08 per mil lebih besar dari target indikator. Pada semester 1 tahun 2019 adalah 144,99 per mil, di bawah target indikator, b. Rata-rata capaian peserta Prolanis rutin berkunjung ke Puskesmas pada semester 1 dan semester 2 tahun 2018 serta semester 1 tahun 2019 berturut-turut adalah 68,68\%; $40,22 \% ; \quad 63,93 \%$ semuanya di atas target indikator, (c) Rata-rata capaian rasio rujukan rawat jalan non spesialistik pada semester 1 dan semester 2 tahun 2018 serta semester 1 tahun 2019 berturut-turut adalah $0,16 \% ; 0,10 \% ; 0,13 \%$ semuanya di atas target indikator, (d) Rata-rata capaian pembayaran kapitasi berbasis komitmen pelayanan Puskesmas di kota Semarang pada semester 1 dan semester 2 tahun 2018 serta semester 1 tahun 2019 berturut-turut adalah 97,74\%; 98,07\%; 98,07\%. Angka ini belum 
mencapai pembayaran kapitasi 100\%, (e) Terdapat 19 (Sembilan belas) Puskesmas (51,35\%) selama bulan Januari sampai dengan Juni tahun 2018 dan 17 (tujuh belas) Puskesmas $(45,94 \%)$ selama bulan Juli sampai dengan Desember tahun 2018 serta 17 (tujuh belas) Puskesmas atau (45,94\%) selama bulan Januari sampai dengan Juni tahun 2019 yang pembayaran kapitasinya tidak terus-menerus mencapai 100\%, (f) Puskesmas Karanganyar adalah Puskesmas dengan rata-rata capaian pembayaran kapitasi terendah selama semester 1 dan semester 2 tahun 2018 serta semester 1 tahun 2019 sebesar 92,50\%. Hal ini berarti terdapat 2 (dua) indikator pembayaran kapitasi berbasis komitmen pelayanan di Puskesmas Karanganyar yang berada di zona tidak aman selama tahun 2018 dan semester 1 tahun 2019. Bagi Puskesmas dengan capaian indikator tidak berada pada zona aman dan capaian pembayaran kapitasi tidak mencapai $100 \%$ perlu dilakukan upaya monitoring terhadap input data pada aplikasi Primary-Care agar diketahui angka capaiannya untuk dilakukan upayaupaya perbaikan sebelum data dikirimkan ke BPJS Kesehatan. Perlu dilakukan penelitian lanjutan untuk menganalisis penyebab tidak tercapainya pembayaran kapitasi $100 \%$ bagi Puskesmas yang capaian pembayarannya rendah, hanya mencapai 92,50\% (dua indikator berada pada zona tidak aman).

\section{Ucapan Terima kasih}

Untuk terselenggaranya penelitian ini, kami mengucapkan terima kasih kepada Poltekkes Kemenkes Semarang dimana sumber dana berasal, Direktur, Ketua Jurusan dan Sekretaris Jurusan RMIK dan Pihak BPJS Kesehatan Regional VI Jawa Tengah dan DIY.

\section{Daftar Pustaka}

Faiza, Hilma (2018). Pelayanan Sistem KBK (Kapitasi Berbasis Komitmen Pelayanan) Jaminan Kesehatan Nasional di Puskesmas Glugur Darat Medan Tahun 2017. Medan: Fakultas Kesehatan Masyarakat Universitas Sumatera Utara.

Kementerian Kesehatan Republik Indonesia. (2013). Buku Pegangan Sosialisasi Jaminan Kesehatan Nasional (JKN) dalam Sistem Jaminan Sosial Nasional. Jakarta:Pusat Komunikasi Publik Kementerian Kesehatan Republik Indonesia.

Letari, Meri. (2017). Analisis Faktor Yang Mempengaruhi Pencapaian Indikator Kapitasi Berbasis Pemenuhan Komitmen Pelayanan Pada Puskesmas di Kota Padang Tahun 2016. Padang: Pasca Sarjana Universitas Andalas.

Notoatmodjo, Soekidjo. 2010. Metodologi Penelitian Kesehatan. Jakarta: Rineka Cipta.

Peraturan Presiden Nomor 82 Tahun 2018 Tentang Jaminan Kesehatan. 2018. Jakarta: Sekretariat Kabinet Republik Indonesia.

Peraturan Badan Penyelenggara Jaminan Sosial Kesehatan Nomor 2 Tahun 2015 Norma penetapan Besaran Kapitasi dan Pembayaran Kapitasi Berbasis Pemenuhan komitmen Pelayanan Pada Fasilitas Kesehatan Tingkat Pertama. 2015. Jakarta: Badan Penyelenggara Jaminan Sosial.

Peraturan Bersama Sekretaris Jenderal Kemenkes RI dan Direktur Utama BPJS Kesehatan Nomor 3 Tahun 2016Petunjuk Teknis Pelaksanaan Pembayaran Kapitasi Berbasis Pemenuhan Komitmen Pelayanan Pada Fasilitas Kesehatan Tingkat Pertama. 2016. Jakarta.

Peraturan Bersama Sekretaris Jenderal Kemenkes RI dan Direktur Utama BPJS Kesehatan Nomor 2 Tahun 2017Petunjuk Teknis Pelaksanaan Pembayaran Kapitasi Berbasis 
Pemenuhan Komitmen Pelayanan Pada Fasilitas Kesehatan Tingkat Pertama. 2017. Jakarta.

Peraturan Menteri Kesehatan Republik Indonesia Nomor 75 Tahun 2014 Pusat Kesehatan Masyarakat. 2014. Jakarta: Kementerian Kesehatan Republik Indonesia.

Profil Kesehatan 2018. Semarang: Dinas Kesehatan Kota Semarang

Purlimaningsih, Ni Putu (2017). Pelaksanaan Kontak Komunikasi Dalam Kapitasi Berbasis Komitmen Pelayanan di Puskesmas Se-Kota
Denpasar. Denpasar: Magister Ilmu Kesehatan Masyarakat Universitas Udayana.

Saryono dan Anggraeni, Mekar Dewi. (2013). Metodologi Penelitian Kualitatif dan Kuantitatif Dalam Bidang Kesehatan. Yogyakarta: Nuha Medika.

Undang-Undang Nomor 24 Tahun 2011 TentangBadan Penyelenggara Jaminan Sosial. 2011. Jakarta.

Undang-Undang No 40 Tahun 2004 Sistem Jaminan Sosial Nasional. 2004. Jakarta. 